\title{
Gambaran Ketidaklengkapan Pengisian Lembar Informed Consent (CM 8) Tindakan Operasi di RSUD Dr.M.Yunus Bengkulu
}

\author{
Niska Ramadani, Djusmalinar, Ice Heliza Putri \\ niskaramadani88@gmail.com \\ Akademi Kesehatan Sapta Bakti Bengkulu
}

\begin{abstract}
ABSTRAK
Penjelasan dalam Informed consent dicatat dan didokumentasikan dalam berkas rekam medis oleh dokter. Kelengkapan data lembar Informed consent sangat penting karena dapat mempengaruhi aspek hukum rekam medis dan mutu rekam medis. Penelitian ini bertujuan untuk mengetahui ketidaklengkapan pengisian lembar informed consent (CM 8) tindakan Operasi pada item variabel (Identifiikasi, Laporan penting dan Autentifikasi) di RSUD dr.M.Yunus Bengkulu Tahun 2016. Jenis penelitian ini adalah penelitian deskriptif, melalui pendekatan cross sectional yaitu melihat kondisi pada saat pelaksanaan penelitian, yang dapat dilakukan sewaktu-waktu. Populasi penelitian ini yaitu berkas rekam medis pasien pada lembar informed consent (CM 8) 10 besar tindakan operasi tahun 2016 yaitu 1022 berkas. Sampel penelitian ini berjumlah 91 lembar informed consent pada berkas rekam medis. Jenis data penelitian ini yaitu data primer, data dikumpulkan menggunakan lembar observasi dan pedoman wawancara. Hasil penelitian ini didapatkan bahwa, dari 91 lembar Informed Consent (IC) yang diobservasi, 100\% lembar IC (CM 8) tindakan operasi tidak terisi lengkap. Persentase tertinggi lembar IC yang tidak lengkap pada item No.KTP (100\%) dan pada item Jenis Kelamin (25\%); persentase tertinggi lembar IC yang tidak lengkap pada item dasar diagnosis (45\%); item alternative dan resiko (44\%) dan perkiraan biaya (100\%), persentase tertinggi lembar IC yang tidak lengkap yaitu pada lembar item TTD saksi rumah sakit $67 \%$ dan nama terang saksi rumah sakit 70\%. Diharapkan RSUD dr. M. Yunus, membuat laporan KLPCM (Ketidaklengkapan Pengisian Catatan Medis) sebagai dasar untuk evaluasi kinerja petugas yang bertanggung jawab terhadap kelengkapan pengisian rekam medis.
\end{abstract}

\section{PENDAHULUAN}

Salah satu parameter untuk menentukan mutu pelayanan kesehatan di rumah sakit adalah data atau informasi dari rekam medis yang baik dan lengkap. Indikator mutu rekam medis yang baik dan lengkap adalah kelengkapan isi, akurat, tepat waktu dan pemenuhan aspek persyaratan hukum (Rachmani, 2010). Kelengkapan dokumen rekam medis merupakan hal yang sangat penting karena berpengaruh terhadap proses pelayanan yang dilakukan oleh petugas medis dan mempengaruhi kualitas dari pelayanan suatu rumah sakit (Indar \& Naiem, 2013). Dalam memberikan pelayanan kesehatan, tenaga kesehatan pemberi pelayanan wajib mencatat semua tindakan yang diberikan kepada pasien, selanjutnya semua yang telah dicatat itu haruslah didokumentasikan secara lengkap, cepat, benar dan dapat dipertanggung jawabkan sebagai bukti yang sah secara hukum yang kita sebut sebagai rekam medis (Huffman, 1994)

Rekam medis merupakan catatan dan dokumen semua tindakan serta pelayanan yang diberikan kepada pasien baik yang dirawat inap maupun rawat jalan atau gawat darurat. Catatan tersebut meliputi identitas, anamnesa, penentuan fisik, laboratorium, Untuk itu pengisian rekam medis harus lengkap agar informasi menjadi akurat (Permenkes, 2008; Permenkes, 2013). Rekam medis juga berguna sebagai bukti tertulis atas tindakan-tindakan pelayanan terhadap seseorang pasien, juga mampu melindungi kepentingan hukum bagi pasien yang bersangkutan, rumah sakit maupun dokter dan tenaga kesehatan lainnya, apabila 
dikemudian hari terjadi suatu hal yang tidak diinginkan menyangkut rekam medis itu sendiri serta sebagai indikator untuk meningkatkan pelayanan kesehatan dirumah sakit (Depkes, 1991; Hatta, 2013).

Isi rekam medis merupakan hak milik pasien sedangkan fisiknya merupakan milik instansi pelayanan kesehatan, untuk itu instansi pelayanan kesehatan harus mengelola, menjaga dan menyimpan rekam medis tersebut dengan benar dan aman. Selain itu instansi pelayanan kesehatan juga harus menjaga kerahasiaan informasi yang ada di dalam rekam medis. Berkas rekam medis merupakan milik sarana pelayanan kesehatan. dengan demikian pimpinan sarana pelayanan kesehatan bertanggung jawab atas hilang, rusak, pemalsuan dan/atau penggunaan oleh orang atau badan yang tidak berhak terhadap rekam medis. Sedangkan isi rekam medis dalam bentuk ringkasan rekam medis merupakan milik pasien. Isi rekam medis dapat diberikan, dicatat, atau dicopy oleh pasien atau orang yang diberi kuasa atau atas persetujuan tertulis pasien atau keluarga pasien yang berhak untuk itu (Menkes, 2008).

Didalam rekam medis terdapat banyak lembar catatan salah satunya adalah lembar persetujuan tindakan kedokteran yang akan dilakukan yang biasa disebut dengan lembar Informed consent. Informed consent adalah persetujuan tindakan kedokteran yang diberikan oleh pasien atau keluarga terdekatnya setelah mendapatkan penjelasan secara lengkap mengenai tindakan kedokteran yang akan dilakukan terhadap pasien tersebut. Penjelasan dalam Informed consent dicatat dan didokumentasikan dalam berkas rekam medis oleh dokter atau dokter gigi yang memberi penjelasan dengan mencantumkan tanggal, waktu, nama dan tanda tangan pemberi penjelasan dan penerima penjelasan (Permenkes RI, 2008).

Kelengkapan data lembar Informed consent sangat penting karena dapat mempengaruhi aspek hukum rekam medis dan mutu rekam medis sehingga diperlukan pelaksanaan yang maksimal untuk pengisian Informed consent (Menkes, 2008). Lembar informed consent termasuk bagian penting dalam proses operasi dan merupakan lembar persetujuan yang memiliki nilai guna dalam kurun waktu selamanya dan tidak boleh di musnahkan (Depkes RI, 2006). Adapun item yang terdapat pada informed consent antara lain item identifikasi, laporan penting, autentikasi. Standar pelayanan minimal kelengkapan pengisian rekam medis termasuk informed consent adalah $100 \%$ (Menkes, 2008).

Kelengkapan pengisian berkas rekam medis dapat menjadi tolak ukur dalam keberhasilan organisasi dalam mencapai tujuan dibidangnya, dimana informed consent juga menjadi salah satu indikator dalam menentukan mutu rekam medis. Namun pada kenyataannya pelaksanaan Informed consent di rumah sakit terkadang belum sesuai dengan peraturan yang ada, masih banyak ketidaklengkapan dalam pengisian lembar informed consent. Masih rendahnya kelengkapan pada pengisian lembar informed consent dapat menentukan kualitas data yang ada dalam lembar informed consent, juga menjadi bukti tertulis oleh rumah sakit bahwa dokter telah memberikan tindakan kedokteran, tindakan medis, serta perawatan kepada pasien dengan adanya persetujuan terlebih dahulu dari pasien atau keluarga pasien (Hatta, 2013).

Hasil penelitian Aisyah (2013) faktor penyebab ketidaklengkapan pada pengisian lembar Informed Consent terdapat pada sumber daya manusia yaitu dokter dan perawat, dimana sebagian besar dokter memiliki sikap ketergantungan dengan perawat, perawat kurang aktif dalam melengkapi isi dari lembar informed consent dan kurangnya komunikasi perawat dengan dokter. Dampak yang timbul apabila 
pengisian lembar informed consent tidak lengkap antara lain waktu operasi dapat berubah diluar rencana jika lembar tidak cepat di isi, disusul dengan kurangnya kelengkapan informed consent maka data pendukung pada pasien akan berkurang, dapat terjadi malpraktek,tidak memenuhi penilaian dalam akreditasi, menghambat dalam pengolahan data rekam medis yang secara tidak langsung mempengaruhi mutu rekam medis, serta dalam bidang hukum sebagai alat pembuktian sebab pada Informed consent terdapat aspek hukum rekam medis (Aisyah, 2013). Untuk itu, perlu adanya peningkatan kesadaran dan kedisiplinan dokter dalam pengisian dokumen rekam medis yaitu dengan diadakan seminar legal aspek rekam medis dan memberikan umpan balik kepada para dokter tentang kelengkapan data rekam medis oleh ketua komite medis setiap rapat komite medis untuk meningkatkan (Yoesana, 2013).

Rumah Sakit Umum Daerah dr.M.Yunus Bengkulu merupakan rumah sakit rujukan tertinggi di kota Bengkulu dan telah terakreditas Paripurna, dimana terdapat jenis pelayanan rawat darurat, rawat jalan dan rawat inap serta melaksanakan dalam berbagai tindakan operasi. Berdasarkan data yang diperoleh dari data pasien operasi di Rumah Sakit Umum Daerah dr.M.Yunus Bengkulu pada bulan Januari - Desember 2016, didapatkan data 10 besar kasus tindakan operasi sebanyak 1022 kasus. Dalam melakukan tindakan operasi Rumah Sakit Umum Daerah dr.M.Yunus Bengkulu melaksanakan prosedur persetujuan sebelum tindakan operasi yaitu pada lembar informed consent (CM 8) guna mengantisipasi apabila dikemudian hari terdapat hal yang tidak diinginkan menyangkut tindakan tersebut.

Survei awal yang dilakukan di Rumah Sakit Umum Daerah dr.M.Yunus Bengkulu peneliti menemukan dari 20 dokumen yang diteliti ada 12 formulir Informed Consent pada tindakan operasi tanpa tanda tangan dari dokter yang menangani tindakan medis atau dokter yang bersangkutan; tidak ada tanda tangan saksi rumah sakit, pemberian informasi, tanda tangan saksi keluarga pasien, tanda tangan yang menyatakan, hal ini akan menjadi masalah dikemudian hari apabila terjadi tuntutan hukum. Mengingat begitu pentingnya informed consent bagi pasien dan dokter dalam melaksanakan tugasnya serta fungsi dari kelengkapan lembar persetujuan tindakan medik apabila terjadi masalah hukum maka penulis tertarik untuk meneliti tentang“" Gambaran ketidaklengkapan pengisian lembar informed consent (CM 8) tindakan operasi di RSUD dr.M.Yunus Bengkulu Tahun 2016". Penelitian ini bertujuan untuk mengetahui ketidaklengkapan pengisian lembar informed consent (CM 8) tindakan Operasi pada item variabel (Identifiikasi, Laporan penting dan Autentifikasi) di RSUD dr.M.Yunus Bengkulu.

\section{METODE PENELITIAN}

Penelitian ini menggunakan jenis penelitian deskriptif yaitu menggambarkan objek yang diteliti secara langsung dengan menggunakan metode observasi dan wawancara, melalui pendekatan cross sectional dimana pendekatan ini dilakukandengan melihat kondisi pada saat pelaksanaan penelitian, yang dapat dilakukan sewaktu-waktu. Populasi penelitian ini yaitu berkas rekam medis pasien pada lembar informed consent (CM 8) 10 besar tindakan operasi tahun 2016 yaitu 1022 berkas. Sampel penelitian ini 91 lembar informed consent pada berkas rekam medis yang dihitung menggunakan rumus besar sampel. Jenis data penelitian ini yaitu data primer, data dikumpulkan menggunakan lembar observasi dan pedoman wawancara.penelitian ini 
dilakukan di unit rekam medis RSUD dr. M. Yunus Bengkulu. Setelah data terkumpul, data dianalisis secara univariat (tabel distribusi frekuensi dan narasi).

\section{HASIL PENELITIAN}

Tabel 1. Distribusi Frekuensi Ketidaklengkapan Pengisian Lembar Informed Consent (CM 8) Tindakan Operasi Di RSUD Dr.M.Yunus Bengkulu Tahun 2016

\begin{tabular}{ccc}
\hline Pengisian Lembar Informed Consent (CM 8) & Jumlah (n) & Persentase (\%) \\
\hline Lengkap & 0 & $0 \%$ \\
\hline Tidak lengkap & 91 & $100 \%$ \\
\hline Total & 91 & $100 \%$ \\
\hline
\end{tabular}

Sumber: Data skunder

Dari tabel 1 di atas menunjukan bahwa dari 91 lembar Informed Consent yang diobservasi, $100 \%$ lembar IC (CM 8) tentang tindakan operasi tidak terisi lengkap.

Tabel 2 . Distribusi Frekuensi Ketidaklengkapan Pengisian Item - Item pada Variabel Identifikasi Lembar Informed Consent (CM 8) Tindakan Operasi di RSUD Dr.M.Yunus Bengkulu

\begin{tabular}{clcccccc}
\hline \multirow{2}{*}{ Variabel } & \multicolumn{2}{c}{ Lengkap } & \multicolumn{2}{c}{ Tidak lengkap } & \multicolumn{2}{c}{ Total } \\
\cline { 3 - 8 } & & $\mathrm{N}$ & $\%$ & $\mathrm{~N}$ & $\%$ & $\mathrm{n}$ & $\%$ \\
\hline 1. & No RM & 69 & 79 & 22 & 21 & 91 & 100 \\
\hline 2. & Nama & 88 & 96,8 & 3 & 3,2 & 91 & 100 \\
\hline 3. & JK & 68 & 75 & 23 & 25 & 91 & 100 \\
\hline 4. & TTL & 81 & 89,1 & 10 & 10,9 & 91 & 100 \\
\hline 5. & Alamat & 82 & 90,2 & 9 & 9.8 & 91 & 100 \\
\hline 6. & No KTP & 0 & 0 & 91 & 100 & 91 & 100 \\
\hline 7. & Tanggal dan tempat & 65 & 72 & 26 & 28 & 91 & 100 \\
\hline
\end{tabular}

Sumber: Data skunder terolah

Dari tabel 2 di atas menunjukan dari 91 lembar Informed Consent (IC) yang diobservasi, persentase terendah lembar IC yang lengkap pada item No.KTP (0\%).
Sedangkan persentase tertinggi lembar IC yang tidak lengkap pada item No.KTP $(100 \%)$ dan pada item Jenis Kelamin (25\%).

Tabel 3. Distribusi Frekuensi Ketidaklengkapan Pengisian Item - Item Pada Variabel Laporan Penting Lembar Informed Consent (CM 8) Tindakan Operasi Di RSUD Dr.M.Yunus Bengkulu

\begin{tabular}{llcccccc}
\hline \multirow{2}{*}{ Variabel } & \multicolumn{2}{c}{ Lengkap } & \multicolumn{2}{c}{ Tidak lengkap } & \multicolumn{2}{c}{ Total } \\
\cline { 3 - 7 } & & $\mathrm{N}$ & $\%$ & $\mathrm{~N}$ & $\%$ & $\mathrm{n}$ & $\%$ \\
\hline 1. & Nama tindakan & 84 & 92,3 & 7 & 7,7 & 91 & 100 \\
\hline 2. & Diagnosis & 64 & 70,3 & 27 & 29,7 & 91 & 100 \\
\hline 3. & Dasar diagnosis & 50 & 55 & 41 & 45 & 91 & 100 \\
\hline
\end{tabular}




\begin{tabular}{|c|c|c|c|c|c|c|}
\hline 4. Indikasi tindakan & 53 & 58,2 & 38 & 41 & 91 & 100 \\
\hline 5. Tata cara tindakan & 53 & 58,2 & 38 & 41 & 91 & 100 \\
\hline 6. Tujuan & 53 & 58,2 & 38 & 41 & 91 & 100 \\
\hline 7. Resiko & 53 & 58,2 & 38 & 41 & 91 & 100 \\
\hline 8. Komplikasi & 53 & 58,2 & 38 & 41 & 91 & 100 \\
\hline 9. $\quad$ Prognosis & 53 & 58,2 & 38 & 41,8 & 91 & 100 \\
\hline 10. Alternatif dan resiko & 51 & 56 & 40 & 44 & 91 & 100 \\
\hline 11. Perkiraan biaya & 0 & 0 & 91 & 100 & 91 & 100 \\
\hline
\end{tabular}

Sumber: Data skunder terolah

Dari tabel 3 di atas menunjukan dari 91 lembar Informed Consent (IC), persentase terendah lembar IC yang lengkap adalah pada item dasar diagnosis (55\%); item alternative dan resiko (56\%) dan perkiraan biaya $(0 \%)$. Sedangkan persentase tertinggi lembar IC yang tidak lengkap pada item dasar diagnosis $(45 \%)$; item alternative dan resiko (44\%) dan perkiraan biaya $(100 \%)$.

Tabel 4. Distribusi Frekuensi Ketidaklengkapan Pengisian Item - Item Pada Variabel Autentifikasi Lembar Informed Consent (CM 8) Tindakan Operasi

Di RSUD Dr.M.Yunus Bengkulu

\begin{tabular}{|c|c|c|c|c|c|c|}
\hline \multirow[t]{2}{*}{ Variabel } & \multicolumn{2}{|c|}{ Lengkap } & \multicolumn{2}{|c|}{ Tidak lengkap } & \multicolumn{2}{|c|}{ Total } \\
\hline & $\mathrm{N}$ & $\%$ & $\mathrm{~N}$ & $\%$ & $\mathrm{~N}$ & $\%$ \\
\hline 1. TTD Dokter & 64 & 70,3 & 27 & 29,7 & 91 & 100 \\
\hline 2. Nama terang dokter & 56 & 62 & 35 & 38 & 91 & 100 \\
\hline 3. TTD pasien & 74 & 81,3 & 17 & 18,7 & 91 & 100 \\
\hline 4. Nama terang pasien & 63 & 70 & 28 & 30 & 91 & 100 \\
\hline 5. TTD saksi pasien & 56 & 62 & 35 & 38 & 91 & 100 \\
\hline 6. Nama terang saksi pasien & 63 & 70 & 28 & 30 & 91 & 100 \\
\hline 7. TTD saksi rumah sakit & 30 & 33 & 61 & 67 & 91 & 100 \\
\hline $\begin{array}{l}\text { 8. Nama terang saksi rumah } \\
\text { sakit }\end{array}$ & 29 & 30 & 62 & 70 & 91 & 100 \\
\hline
\end{tabular}

Sumber: Data skunder

Dari tabel 4 di atas menunjukan bahwa dari 91 lembar Informed Consent (IC) yang diamati, persentase terendah pada lembar IC yang lengkap yaitu pada item TTD saksi rumah sakit dan nama terang saksi rumah

\section{PEMBAHASAN}

\section{Gambaran Ketidaklengkapan Pengisian Lembar Informed Consent (CM 8) Tindakan Operasi}

Hasil penelitian ini didapatkan dari

91 lembar informed consent yang diobservasi keseluruhan (100\%) lembar Informed Consent (IC) tidak lengkap. Standar pelayanan minimal kelengkapan sakit masing-masing 33\% (30 lembar) dan $30 \%$ (29 lembar). Sedangkan persentase tertinggi lembar IC yang tidak lengkap yaitu pada lembar item TTD saksi rumah sakit $67 \%$ dan nama terang saksi rumah sakit $70 \%$. pengisian lembar informed consent adalah $100 \%$. Kelengkapan berkas rekam medis sangat penting dilakukan salah satunya pada lembar informed consent. Dilihat dari salah satu kegunaannya adalah dapat dijadikan sebagai alat bukti hukum apabila terjadi gugatan, serta secara tidak langsung dapat mempengaruhi mutu rekam medis itu sendiri. Maka dari itu kelengkapan 
informed consent harus diisi secara lengkap (Permenkes, 2008).

Hasil penelitian ini didapatkan bahwa tidak semua dokter mengisi pada lembar informed consent sesuai dengan tanggung jawabnya, masih kebanyakan perawat yang mengisikan pada lembar informed consent kemudian dokter tinggal menandatangani lembar tersebut, akan tetapi hal tersebut belum mendapat perhatian dari dokter dikarenakan kesibukan dokter serta tingkat kesadaran dalam melengkapi rekam medis salah satunya informed consent. Untuk memperoleh persetujuan dari pasien dan untuk menghindari adanya salah satu pihak yang dirugikan maka dokter wajib memberikan informasi sejelas-jelasnya agar pasien dapat mempertimbangkan apa yang akan terjadi terhadap dirinya (Suprapti, 1994). Menurut Permenkes RI No 290/Menkes/Per/III/2008 tentang persetujuan tindakan kedokteran, penjelasan harus dicatat dan didokumentasikan didalam berkas rekam medis oleh dokter yang memberikan penjelasan dengan mencantumkan tanggal, waktu, nama dan tanda tangan pemberi dan penerima penjelasan.

Hasil penelitian ini sejalan dengan hasil penelitian Aisyah (2013), yaitu berdasarkan studi dokumentasi dari 251 berkas yang dianalisis terdapat 95 lembar informed consent lengkap $(38,13 \%), 49$ lembar tidak lengkap $(19,41 \%)$ dan 107 lembar tidak terisi $(42,43 \%)$. Berdasarkan wawancara dan observasi faktor penyebab ketidaklengkapan terdapat pada sumber daya manusia yaitu dokter dan perawat. Sebagian besar dokter yang melakukan operasi adalah dokter tamu, kesibukan dokter, ketergantungan dokter terhadap perawat, kurangnya kesadaran dokter untuk melengkapi, kurangnya keaktifan perawat untuk melengkapi, kurangnya komunikasi perawat dengan dokter.

\section{Ketidaklengkapan pengisian Item pada Variabel Identifikasi Lembar Informed Consent}

Identitas pasien merupakan proses pengumpulan data pertama sebelum pelayanan di fasilitas kesehatan. Data ini juga yang dijadikan dasar untuk pelayanan medis dan pelaporan. Pengisian identitas pasien harus dilaksanakan dengan benar, teliti, akurat, dan lengkap. Sebaiknya identifikasii pasien dilakukan sebelum pasien dirawat/diperiksa dengan meminta atau mewawancarai pasien sendiri namun apabila tidak mungkin maka dimintakan keterangan kepada keluarga terdekat pasien. Pengumpulan identifikasi pasien ini juga harus didukung dengan bukti legal pasien seperti KTP, SIM, kartu mahasiswa, dan lain-lain (Budi, 2011).

Hasil penelitian ini didapatkan bahwa dari 91 lembar Informed Consent (IC) yang diobservasi, persentase tertinggi lembar IC yang tidak lengkap yaitu pada item No.KTP dan pada item Jenis Kelamin. Hal ini disebabkan karena petugas tidak patuh dalam melakukan pengisian lembar informed consent dan protap yang belum tersosialisasi. Hasil penelitian ini sejalan dengan hasil penelitian Kencananingtyas (2014), pengisian identitas keluarga pasien yang mengisi formulir Informed Consent terendah pada pengisian No.KTP/SIM (100\%), hal tersebut tidak diisi karena untuk keefektifan waktu dalam pengisian formulir dan kurangnya pengetahuan pihak pasien arti pentingnya pengisian nomor identitas diri dan sebagai bukti keabsahan dalam suatu perkara.

Hasil penelitian Octaria \& Trisna (2015), kelengkapan untuk pengisian identitas pasien untuk alamat pasien 
mencapai 82 (85.4\%) diisi tidak lengkap. Begitu juga untuk ketidaklengkapan pengisian identitas penanggung jawab pasien untuk alamat $71(74.0 \%)$ di isi tidak lengkap. Menurut Budi (2011), belum maksimalnya pengisian lembar informed consent khususnya pada variabel identitas pasien akan mengakibatkan pelayanan pada pasien menjadi terhambat dan membuat pasien atau keluarga pasien bingung dalam mengambil keputusan.

\section{Ketidaklengkapan pengisian Item pada Variabel Laporan Penting Lembar Informed Consent}

Dari 91 lembar Informed Consent (IC), persentase tertinggi lembar IC yang tidak lengkap pada item dasar diagnosis (45\%); item alternative dan resiko (44\%) dan perkiraan biaya (100\%). Hasil penelitian Pamungkas dkk (2010), persentase rata-rata ketidaklengkapan review laporan yang penting adalah $33,31 \%$. Item yang paling tinggi ketidaklengkapannya adalah informasi penunjang dengan rata-rata ketidaklengkapan 98,94\%.

Jenis informasi yang harus dituliskan oleh dokter di lembar informed consent meliputi nama tindakan, diagnosis, dasar diagnosis, indikasi tindakan, tata cara tindakan, tujuan, resiko, kompliksai, prognosis, alternative dan resiko serta perkiraan biaya (Permenkes, 2008). Pernyataan ini didukung oleh Undang-Undang No 29 tahun 2004 tentang praktik kedokteran yang menyatakan bahwa dalam melakukan prosedur, adanya keharusan membuat persetujuan tertulis apabila adanya tindakan operatif atau invasif yang beresiko tinggi. Hal ini berkaitan dengan guna informed consent sebagai alat bukti bahwa dokter telah memenuhi prosedur yang diharuskan.

\section{Ketidaklengkapan pengisian Item pada Variabel Autentifikasi Lembar Informed Consent}

Hasil penelitian ini didapatkan bahwa dari 91 lembar Informed Consent (IC) yang diamati khususnya pada variabel Autentifikasi, pada item TTD dan nama terang saksi rumah sakit merupakan persentase tidak lengkap yang paling tinggi. Hasil penelitian ini berbeda dengan hasil penelitian Rahayu (2014) didapatkan bahwa dokumen informed consent yang tidak lengkap sebesar $47 \%$. Dari 40 lembar informed consent yang diobservasi, persentase kelengkapan paling rendah yaitu pada item tanda tangan oleh saksi keluarga sebesar $63 \%$. Hasil penelitian Rahayu sejalan dengan Octaria \& Trisna (2015), berdasarkan autentikasi kelengkapan pengisian formulir informed consent untuk jenis tindakan medic mencapai 57 (59.4\%) tidak diisi dengan lengkap, dan juga untuk pengisian istilah medis jumlah tertinggi mencapai $51(53.1 \%)$ tidak diisi dengan lengkap. Begitu juga dengan nama dan tanda tangan saksi I yaitu dari pihak pasien sebanyak $44(45.8 \%)$ tidak diisi dengan lengkap. Hasil penelitian Pamungkas (2010), didapatkan bahwa rata-rata ketidaklengkapan pengisian berkas rekam medis pada komponen autentifikasi sebanyak 42,55 \%. Item yang memiliki tingkat ketidaklengkapan yang tertinggi adalah item nama dokter pada lembar RM 4 yaitu sebanyak $94,68 \%$.

Menurut Depkes RI (2006), apabila formulir tidak terdapat nama penanggung jawab, mengakibatkan petugas sulit menentukan pihak yang bertanggungjawab dalam pelayanan yang diberikan kepada pasien. 
Ketidaklengkapan pengisian variabel autentifikasi akan berdampak dapat merugikan berbagai pihak bukan hanya pasien tetapi dokter dan rumah sakit dapat dirugikan apabila terjadinya kesalahan dalam pemberian obat/tindakan serta menentukan kualitas data yang ada dalam lembar informed consent, juga menjadi bukti tertulis oleh rumah sakit bahwa dokter telah memberikan tindakan kedokteran, tindakan medis, serta perawatan kepada pasien dengan adanya persetujuan terlebih dahulu dari pasien atau keluarga pasien (Hatta, 2013).

\section{SIMPULAN}

Berdasarkan hasil dan pembahasan mengenai gambaran ketidaklengkapan pengisian lembar informed consent (CM 8) tindakan operasi di RSUD dr.M.Yunus Bengkulu tahun 2016 dapat disimpulkan :

1. Dari 91 lembar Informed Consent (IC) yang diobservasi, 100\% lembar IC (CM 8) tindakan operasi tidak terisi lengkap

2. Dari 91 lembar Informed Consent (IC) yang diobservasi, persentase terendah lembar IC yang lengkap pada item No.KTP $(0 \%)$. Sedangkan persentase tertinggi lembar IC yang tidak lengkap pada item No.KTP (100\%) dan pada item Jenis Kelamin (25\%)

3. Dari 91 lembar Informed Consent (IC), persentase terendah lembar IC yang lengkap adalah pada item dasar diagnosis $(55 \%)$; item alternative dan resiko $(56 \%)$ dan perkiraan biaya $(0 \%)$. Sedangkan persentase tertinggi lembar IC yang tidak lengkap pada item dasar diagnosis (45\%); item alternative dan resiko $(44 \%)$ dan perkiraan biaya (100\%)

4. Dari 91 lembar Informed Consent (IC) yang diamati, persentase terendah pada lembar IC yang lengkap yaitu pada item TTD saksi rumah sakit dan nama terang saksi rumah sakit masing-masing 33\% (30 lembar) dan $30 \%$ (29 lembar). Sedangkan persentase tertinggi lembar IC yang tidak lengkap yaitu pada lembar item TTD saksi rumah sakit $67 \%$ dan nama terang saksi rumah sakit $70 \%$.

\section{SARAN}

Berdasarkan hasil pada kesimpulan di atas, maka dapat disusun saran sebagai berikut:

1. Melakukan sosialisasi dan evaluasi serta audit terkait kelengkapan pengisian lembar informed consent.

2. Membuat laporan KLPCM (Ketidaklengkapan Pengisian Catatan Medis) sebagai dasar untuk evaluasi kinerja petugas yang bertanggung jawab terhadap kelengkapan pengisian rekam medis.

3. Melaksanakan pelatihan bagi petugas yang bertanggung jawab terhadap kelengkapan pengisian rekam medis terkhusus Informed Consent.

\section{DAFTAR PUSTAKA}

Aisyah, S. Faktor-Faktor Yang Menyebabkan Ketidaklengkapan Pengisian Lembar Informed Consent Tindakan Bedah Mata Di Rs. Mata "Dr. Yap" Yogyakarta. Universitas Gadjah Mada, 2013. http://etd.repository.ugm.ac.id/index.php

Budi, S.C. 2011. Manajemen Unit Kerja Rekam Medis. Yogyakarta: Quantum Sinergis Media.

Departemen Kesehatan Republik Indonesia. 1991. Petunjuk Teknis Penyelenggaraan Rekam Medis/Medical Record Rumah Sakit. Jakarta.

Departemen Kesehatan Republik Indonesia Dirjen Yanmed. Pedoman Pengelolaan Rekam Medis Rumah Sakit di Indonesia. Jakarta : Depkes 2006.

Departemen Kesehatan Republik Indonesia. 2006. Pedoman Penyelenggaraan dan Prosedur Rekam Medis Rumah Sakit di Indonesia Revisi II. Jakarta : Depkes RI 
Hatta, G.R (2013). Pedoman Manajemen Informasi Kesehatan di Sarana Pelayanan Kesehatan. Jakarta: Penerbit Universitas Indonesia

Huffman, E. K. Health Information Management. Ilyonis : Physician record company. 1994.

Indar, I dan Naiem, M.F. Faktor yang Berhubungan dengan Kelengkapan Rekam Medis di RSUD H. Podjanga DG. Ngalle Takalar 2013. Jurnal Administrasi dan Kebijakan Kesehatan Indonesia. 2013; 2(2): 10-18.

Kencananingtyas, S.A., Lestari,T., Harjanti. Pelaksanaan Pemberian Informed Consent Dan Kelengkapan Informasi Di RSU Jati Husada Karanganyar Tahun 2014. Jurnal Manajemen Informasi Kesehatan Indonesia, ISSN:2337-585X, Vol.3, No.1, Oktober 2014

Menteri Kesehatan Republik Indonesia, 2008.Peraturan Menteri Kesehatan Nomor 290/Menkes/Per/III/2008 Tentang Persetujuan Tindakan Kedokteran, Jakarta: Departemen Kesehatan Republik Indonesia

Menteri Kesehatan Republik Indonesia. Peraturan Menteri Kesehatan Republik Indonesia Nomor 269/ MENKES/ PER/ III/ 2008 tentang Rekam Medis. Jakarta : Departemen Kesehatan RI, 2008

Menteri Kesehatan Republik Indonesia, 2013. Peraturan Menteri Kesehatan Nomor 55 tentang Rekam Medis, Jakarta: Departemen Kesehatan Republik Indonesia.

Octaria, H dan Trisna, W.V. 2015. Pelaksanaan Pemberian Informasi dan Kelengkapan
Informed Consent di Rumah Sakit Umum Daerah Bangkinang (RSUD Bangkinang). Jurnal Kesehatan Komunitas, Vol. 3, No. 2, Mei 2016

Pamungkas, T.W., Marwati, T., Solikhah. Analisis Ketidaklengkapan Pengisian Berkas Rekam Medis Di Rumah Sakit PKu Muhammadiyah Yogyakarta. KES MAS UAD Vol. 4, No. 1, Januari $2010: 1-75$. ISSN : 1978-0575

Rachmani E. Analisa Keterlambatan Penyerahan Dokumen Rekam Medis Rawat Inap di Rumah Sakit POLRI dan TNI Semarang. Jurnal Rekam Medis. 2010; Semarang. 2012.9(2): 107-117

Rahayu, S. 2014. Hubungan Penerapan Kebijakan dengan Kelengkapan Dokumentasi Informed Consent di Bangsal Cendana RSUP Dr. Sardjito Yogyakarta. Skripsi. Stikes Aisyiyah Yogyakarta

Suprapti, R, S. (1994). Etika kedokteran Indonesia.Jakarta: Fakultas Kedokteran Indonesia.

Undang-Undang RI No 29 tahun 2004 Tentang Praktik Kedokteran

Yoesana U. Hubungan antara Motivasi Kerja dengan Disiplin Kerja Pegawai di Kantor Kecamatan Muara Jawa Kabupaten Kutai Kartanegara. Jurnal Pemerintahan Integratif. 2013; 1(1): 13-27. 